Journal of Industrial and Engineering System (JIES)

e-ISSN: 2722-7979

Vol. 1 No. 2, Hal 89-100

\title{
Analisis Perbaikan Kualitas Pelayanan Menggunakan Metode Quality Function Deployment (Studi Kasus Cafe XYZ Rawalumbu)
}

\author{
Alloysius Vendhi Prasmoro*1, Chusnul Chotimah ${ }^{2}$, Denny Siregar ${ }^{3}$ \\ Teknik Industri Fakultas Teknik, Universitas Bhayangkara Jakarta \\ e-mail: ${ }^{1}$ alloysius.vendhi@dsn.ubharajaya.ac.id,,*2 chotimahchusnul099@ gmail.com, \\ denny.siregar@dsn.ubharajaya.ac.id
}

*Korespondensi: alloysius.vendhi@dsn.ubharajaya.ac.id

\begin{abstract}
Culinary business in Bekasi is growing more and more, both cafes or other fast food restaurants. This encourages entrepreneurs, investors to do culinary business. One of the fast food culinary businesses is the XYZ cafe. This study discusses the analysis of service quality in XYZ cafe about voice of customers to increase customer satisfaction at XYZ cafe. The purpose of this study is to determine the priority scale to increase the customers satisfaction based on the voice of customer and know what technical requirements should be given by cafe XYZ to does what customers need. The method used is the QFD, using the matrix house of quality. The results of this study are 15 Voice OF customer attributes that have also been sorted by priority scale of improvement, with the first priority being the taste of delicious and fresh and there are 8 attributes of technical requirements
\end{abstract}

Keywords: Service Quality, Voice of Customer, customer satisfaction, Quality Function Deployment (QFD), House of Quality

\begin{abstract}
ABSTRAK
Bisnis kuliner di kota Bekasi berkembang semakin banyak, baik cafe ataupun restoran cepat saji lainnya. Hal ini mendorong para pengusaha dan investor untuk berbisnis kuliner, serta membuat semakin banyaknya persaingan. Salah satu usaha kuliner cepat saji adalah cafe XYZ. Penelitian ini membahas tentang analisis kualitas pelayanan di cafe XYZ terhadap kebutuhan konsumen yang bertujuan untuk meningkatkan kepuasan pelanggan terhadap cafe XYZ. Tujuan penelitian ini adalah mengetahui skala prioritas apa yang sebaiknya dilakukan cafe XYZ untuk memenuhi keinginan pelanggan berdasarkan voice of customer serta mengetahui persyaratan teknis apa saja yang sebaiknya diberikan oleh cafe XYZ untuk memenuhi kebutuhan dan keinginan pelanggannya berdasarkan skala prioritas. Metode pengolahan data yang dilakukan adalah metode $Q F D$ dengan menggunakan matrix house of quality. Hasil penelitian ini terdapat 15 atribut Voice OF customer yang juga telah diurutkan berdasarkan skala prioritas perbaikan, dengan prioritas utama adalah cita rasa menu lezat dan fresh serta terdapat 8 atribut persyaratan teknis.
\end{abstract}

Kata kunci: Kualitas Pelayanan, Voice of Customer, kepuasan pelanggan, Quality function Deployment (QFD), House Of Quality

\section{PENDAHULUAN}

Bisnis kuliner di masa kini semakin banyak baik cafe bistro ataupun restoran fast food lainnya sehingga mendorong pengusaha dan investor untuk terjun langsung terhadap bisnis kuliner. Kota Bekasi merupakan salah satu kota strategis karena wilayahnya berdekatan dengan ibukota DKI Jakarta serta merupakan kota dengan sektor industri terbanyak, hal tersebut membuat kota Bekasi menjadi padat penduduk dan belum lagi banyaknya orang yang berdatangan ke kota Bekasi.

Dengan banyaknya penduduk di kota Bekasi dan sebagian besar adalah generasi milenial yang selalu ingin eksis dan penasaran untuk mencoba hal hal baru serta diiringi oleh perkembangan zaman, beragam kuliner termasuk cafe dan bistro mulai bermunculan. Pada mulanya orang mengenal cafe hanya sebagai tempat menikmati kopi saja, tetapi seiring berjalannya waktu, cafe telah berubah 
Alloysius Vendhi Prasmoro, Chusnul Chotimah, Denny Siregar

Submitted: 09/10/2020; Revised: 10/10/2020; Accepted: 12/10/2020; Published: 29/12/2020

dengan beragam konsep yang mengusung tematema mengikuti perkembangan zaman, diantaranya sebagai tempat menikmati hidangan. Begitu banyak tersebarnya cafe-cafe di Bekasi memicu persaingan ketat antar pengusaha café, seperti cafe XYZ dan cafe 123 yang saat ini berfokus pada pengolahan mie. Para pengusaha cafe dituntut untuk mempertahankan maupun meningkatkan kualitas citra dan kualitas produk yang ditawarnya.

Pelayanan yang baik dapat memengaruhi kepuasan pelanggan, maka penting bagi pihak cafe untuk memerhatikan kualitas pelayanannya, guna memuaskan para pelanggannya dan dapat bersaing dengan cafe kompetitor seperti cafe 123 yang juga berfokus pada pengolahan mie. Namun, semakin banyak yang telah mengenal cafe ini justru keluhan dari pelanggan yang datang pun kerap kali bermunculan, serta masalah lain yang muncul pada cafe ini adalah menurunnya jumlah minat pelanggan yang menyebabkan 2 cabang di cafe ini tutup serta menurun drastisnya omzet dalam beberapa bulan terakhir yang biasanya mendapatkan omzet minimal sebesar 30 juta rupiah perbulannya, namun terjadi penurunan pesat dalam beberapa bulan terakhir, sehingga pihak manajemen cafe terpaksa harus memberhentikan beberapa karyawannya. Tabel 1 merupakan keuntungan yang diperoleh cafe XYZ berdasarkan hasil wawancara dengan pihak pengelola cafe pada periode bulan Januari 2019 sampai dengan bulan Desember 2019.
Tabel 1 Keuntungan Cafe XYZ Tahun 2019

\begin{tabular}{lll}
\hline Bulan & $\begin{array}{l}\text { Tahun } \\
(\mathrm{Rp})\end{array}$ & $\begin{array}{l}\text { Persentase } \\
(\%)\end{array}$ \\
\hline Januari & 35.180 .000 & 10 \\
Februari & 35.380 .000 & 10 \\
Maret & 32.050 .000 & 9 \\
April & 32.750 .000 & 9 \\
Mei & $31.940 .00 ` 0$ & 9 \\
Juni & 30.320 .000 & 8 \\
Juli & 29.510 .000 & 8 \\
Agustus & 30.320 .000 & 8 \\
September & 27.080 .000 & 8 \\
Oktober & 25.460 .000 & 7 \\
November & 24.650 .000 & 7 \\
Desember & 23.030 .000 & 6 \\
JUMLAH & 357.670 .000 & 100 \\
Rata Rata & 29805833 & 8 \\
\hline \multicolumn{4}{c}{ Bersadarkan tabel 1} & dapat ditarik
\end{tabular}

kesimpulan bahwa keuntungan cafe XYZ berada di posisi yang tidak stabil yang cenderung mengalami penurunan pada tahun 2019 dan penurunan berturut turut terjadi pada bulan September 2019 sampai dengan bulan Desember 2019. Pihak pengelola cafe memprediksi adanya kemungkinan jenuhnya pelanggan terhadap produk dan pelayanan yang ditawarkan oleh pihak cafe XYZ karena kurangnya inovasi terhadap pengembangan produk dan pelayanan. Di samping itu belum adanya penelitian sebelumnya tentang analisis kepuasan terhadap pelayanan di cafe XYZ. maka dari itu perlu dilakukan adanya analisis perbaikan untuk mengetahui tingkat kepentingan (keinginan pelanggan) guna mempertahankan serta meningkatkan jumlah pelanggan yang tertarik untuk mengunjungi cafe ini. Serta timbulnya kepuasan pelanggan karena pelayanan yang diterapkan menjadi lebih baik.

Berikut tabel beberapa ulasan tentang keluhan yang disampaikan oleh beberapa pelanggan yang pernah berkunjung, yang didapat melalui wawancara dengan beberapa orang dan penyampaian kotak saran ataupun ulasan. Perhatikan tabel 2 sebagai berikut. 
Tabel 2 Ulasan Keluhan Pelanggan

\begin{tabular}{|c|c|c|}
\hline No & Keluhan & Kategori \\
\hline 1 & $\begin{array}{l}\text { Cita rasa menu yang } \\
\text { tidak konsisten }\end{array}$ & Tangible \\
\hline 2 & $\begin{array}{l}\text { Pelengkap menu yang } \\
\text { diantar ke meja } \\
\text { pesanan kurang }\end{array}$ & Reliability \\
\hline 3 & $\begin{array}{l}\text { Respon pelayan yang } \\
\text { kurang cepat sehingga } \\
\text { pelanggan terlalu } \\
\text { lama menunggu } \\
\text { pesanan yang datang }\end{array}$ & $\begin{array}{l}\text { Reliability } \\
\text { dan } \\
\text { Responsiv } \\
\text { eness }\end{array}$ \\
\hline 4 & Jaringan internet sulit & Tangible \\
\hline 5 & $\begin{array}{l}\text { Bebas masuknya } \\
\text { pengamen yang } \\
\text { menyebabkan tidak } \\
\text { nyaman }\end{array}$ & Assurance \\
\hline
\end{tabular}

Berdasarkan permasalahan tersebut. maka untuk dapat meningkatkan kualitas produk sesuai dengan keinginan pelanggan. penulis menggunakan alat bantu analisis dari Quality Function Deployment (QFD) yaitu House of Quality (HOQ). QFD adalah proses yang menentukan kebutuhan konsumen yang kemudian diolah menjadi atribut-atribut pada area fungsi yang dapat diubah atau diperbaiki oleh perusahaan. HOQ adalah salah satu alat dari QFD. HOQ merupakan kerangka yang dapat membantu perusahaan untuk mengetahui keinginan dan kebutuhan konsumen yang kemudian melakukan perbaikan dengan karakteristik teknik yang dimiliki perusahaan. Oleh karena itu maka perlu dilakukannya penelitian di cafe XYZ dengan judul penelitian yaitu analisis perbaikan kualitas pelayanan dalam upaya meningkatkan kepuasan pelanggan menggunakan metode quality function deployment (studi kasus cafe xyz rawalumbu).

Berdasarkan uraian latar belakang di atas maka dalam hal ini rumusan masalah pada penelitian ini adalah:

1. Skala prioritas apa yang sebaiknya dilakukan perbaikan oleh cafe XYZ untuk memenuhi kebutuhan dan keinginan pelanggannya berdasarkan hasil pembobotan atribut jasa

2. Karakteristik atau persyaratan teknis apa saja yang sebaiknya diberikan oleh cafe XYZ untuk memenuhi kebutuhan dan keinginanp elanggannya berdasarkan skala pembobotan prioritas
Penelitian ini bertujuan untuk:

1. Mengetahui skala prioritas apa yang sebaiknya dilakukan perbaikan oleh cafe XYZ untuk memenuhi keinginan pelanggan berdasarkan voice of customer berdasarkan hasil pembobotan atribut jasa,

2. Mengetahui karakteristik atau persyaratan teknis apa saja yang sebaiknya diberikan oleh cafe XYZ untuk memenuhi kebutuhan dan keinginan pelanggannya berdasarkan skala pembobotan prioritas.

\section{Pengertian Pelayanan}

Menurut Wijaya (2018), pelayanan merupakan suatu tindakan atau kegiatan yang ditawarkan oleh satu pihak kepada pihak lain. yang pada dasarnya tidak berwujud dan tidak mengakibatkan kepemilikan apapun.

Menurut Zeithaml dan M.J Bitner (2009) dalam (Pratiwi et al., 2017). Terdapat 5 dimensi kualitas pelayanan yang harus diwujudkan. yaitu:

1. Tangibles (Bukti Langsung). Merupakan wujud fisik yang ditampilkan atau fasilitas yang dapat dilihat dan dirasakan oleh pelanggan. Contohnya seperti desain interior cafe. fasilitas yang digunakan serta penampilan pelayan

2. Reliability (Keandalan). Merupakan kemampuan dalam memberikan jasa yang dijanjikan secara handal dan tepat

3. Responsive (Daya Tanggap). Merupakan kemampuan untuk membantu konsumen serta dapat memberikan pelayanan dengan sigap.

4. Empathy (Kepedulian). Merupakan suatu bentuk kepedulian yang diberikan pelayan kepada konsumen, seperti kemampuan pelayan untuk mengerti kebutuhan konsumen.

5. Assurance (Jaminan). Merupakan pengetahuan. etika dalam memberikan pelayanan. serta kemampuan karyawan terhadap produk yang ditawarkan secara tepat untuk menumbuhkan rasa keyakinan dan kepercayaan konsumen.

\section{Pengertian Kepuasan Pelanggan}

Menurut Kondrotaite (2012) dalam Sariffudin (2017), mengatakan bahwa kepuasan pelanggan terhadap layanan yang disediakan 
Alloysius Vendhi Prasmoro, Chusnul Chotimah, Denny Siregar

Submitted: 09/10/2020; Revised: 10/10/2020; Accepted: 12/10/2020; Published: 29/12/2020

merupakan faktor penting dalam hal peningkatan pelayanan.

\section{Metode Quality Function Deployment}

Menurut Wijaya (2018). QFD merupakan praktik untuk merancang proses sebagai tanggapan terhadap kebutuhan pelanggan. QFD itu terdiri atas beberapa aktivitas berikut:

1. Penjabaran persyaratan yang dituntut pelanggan

2. Penjabaran karatkeristik kualitas yang dapat diukur.

3. Penentuan hubungan antara kebutuhan kualitas dan karakteristik kualitas.

4. Penerapan nilai-nilai berdasarkan angkaangka tertentu terhadap masing-masing karakteristik kualitas.

5. Perancangan. produksi dan pengendalian kualitas produk

QFD berusaha menerjemahkan apa yang dibutuhkan pelanggan menjadi apa yang dihasilkan oleh organisasi. Tujuan QFD adalah menjamin bahwa produk yang dihasilkan dapat memenuhi tingkat kualitas yang diperlukan sehingga benar-benar dapat memuaskan kebutuhan para pelanggan.

\section{Tahap-tahap Analisis Quality Functon Deployment}

1. Penentuan kriteria kualitas pelanggan. Terdiri dari lima dimensi kualitas jasa yang diterjemahkan ke dalam persyaratan sekunder dan tersier

2. Aspek jasa perusahaan. Terdiri dari elemenelemen perencanan prosedur dalam desain sistem penyampaian jasa ditulis dalam satu baris arah vertikal.

3. Bobot skor. Merupakan hasil rata-rata skor untuk seluruh kualitas tersier.

4. Relative importance ranking. Perengkingan elemen-elemen berdasarkan tinngkat kepentingannya.

5. Critcal incident. Jumlah keluhan pelanggan atau konsumen atas kegagalan penyampaian jasa dalam satu periode waktu.

6. Competitive benchmark. Perbedaan skor kepuasan antara jasa pada perusahaan dengan perusahaan pesaing.

7. Jaringan keterkaitan. Jaringan yang berisi siombol-simbol di kuantifikasi dengan skala $9: 3: 1$. Artinya jika hubungan itu kuat bernilai 9. jika sedang bernilai 3 dan jika lemah bernilai 1.
8. Importance ranking. Merupakan ranking dari bobot keseluruhan dari aspek perusahaan.

9. Matriks korelasi. Kekuatan hubungan antar aspek-aspek perusahaan untuk menunjukkan kepentingan kerja sama antar departemen yang berbeda.

\section{METODE PENELITIAN \\ Metode Pengumpulan Data}

Jenis data pada penelitian ini terdiri dari data sekunder dan data primer baik yang bersifat kualitatif maupun kuantitatif. Dalam penelitian ini digunakan beberapa teknik pengumpulan data sebagai berikut :

1. Observasi Lapangan

Observasi yang dilakukan adalah dengan pengamatan langsung terhadap kegiatan pelayanan di cafe XYZ Rawalumbu.

2. Wawancara (Kuesioner)

Wawancara dengan menyebarkan kuesioner kepada konsumen yang pernah berkunjung ke cafe XYZ Rawalumbu. Skala pengukuran yang digunakan dalam penelitian ini adalah skala Likert. dengan interval penilaian

untuk setiap jawaban responden. Skala ini mempunyai 5 tingkatan yang dimulai dari : skor 1 = sangat tidak puas / sangat tidak penting.

skor $2=$ tidak puas / tidak penting

skor $3=$ netral

skor $4=$ puas $/$ penting

skor 5 = sangat puas / sangat penting.

3. Studi Pustaka

Studi Pustaka yaitu teknik pengumpulan data dengan cara mempelajari dokumendokumen perusahaan,buku-buku kepustakaan, laporan-laporan penelitian yang sudah ada serta sumber lain yang berhubungan dengan penelitian ini.

\section{Populasi dan sampel}

Populasi pada penelitian adalah pelanggan cafe XYZ, yang bersedia untuk mengisi kuesioner kepuasan dan kepentingan terhadap persyaratan pelanggan di cafe XYZ.

Pada penelitian ini metode yang digunakan untuk menentukan jumlah sampel adalah dengan menggunakan rumus Slovin sebagai berikut:

$\mathrm{n}=\frac{\mathrm{N}}{1+\mathrm{Ne}^{2}}$

Analisis Perbaikan Kualitas Pelayanan Menggunakan Metode Quality Function Deployment (Studi Kasus Cafe XYZ Rawalumbu) Journal of Industrial and Engineering System 1 (2): Desember 2020 
Alloysius Vendhi Prasmoro, Chusnul Chotimah, Denny Siregar

Submitted: 09/10/2020; Revised: 10/10/2020; Accepted: 12/10/2020; Published: 29/12/2020

Dimana:

$\mathrm{n}=$ Ukuran Sampel

$\mathrm{e}=5 \%$ kelonggaram ketidak telitian karena kesalahan

$\mathrm{N}=$ Ukuran Populasi

$\mathrm{n}=\frac{55}{1+55 \times 0.0025}=49$ Responden

\section{Uji Validitas dan Reliabilitas}

1. Uji Validitas

Uji Validitas dilakukan untuk mengetahui apakah atribut atribut yang terdapat pada kuesioner yang diajukan valid atau tidak. sebuah kuesioner dikatakan valid jika butir pada pertanyaan tersebut memeliki keterkaitan yang tinggi. biasanya di cerminkan oleh hubungan antara jawaban dan pertanyaan. Pada penelitian ini uji validitas menggunakan spss 23 dengan signifikansi sebesar 5\% (0.05).

2. Uji Reliabilitas

Uji reliabilitas pada penelitian ini ditujukan untuk mengetahui apakah hasil kuesioner yang telah diperoleh bersifat reliabel atau tidak. Menurut Ervini et al (2018). suatu kuesioner dikatakan handal atau reliabel jika jawaban seseorang terhadap pertanyaan bersifat konsisten dari waktu ke waktu. Pada penelitian ini uji reliabilitas menggunakan spss 23 dengan menggunakan uji statistik cronbach's alpha dan dapat dikatakan reliabel apabila nilai cronbach's alpha $>0.60$.

Analisis Data dengan Menggunakan Metode QFD

Sebelum melakukan pengisian matriks house of quality maka diperlukan pembuatan matriks perencanaan yang terdiri dari:
1. Tingkat
Kepentingan
Konsumen
(Importance to Costumer)

2. Tingkat Kepuasan Konsumen (Current Satisfaction Performance)

3. Nilai Target (Diperoleh dari pihak manajemen cafe. Penilaian menggunakan skala likert).

4. Improvement Ratio (Rasio Perbsikan)

5. Sales Point

6. Sales point disimbolkan dengan angka sebagai berikut :

$1=$ Tidak Ada Sales Point.

$1.2=$ Sales Point Sedang.

$1.5=$ Sales Point Kuat
7. Absolute Weight and Normalized Raw Weight.

8. Digunakan untuk menunjukkan besarnya perbaikan suatu kriteria customer need

9. Matriks Hubungan (Relationship Matrix) Matriks ini digunakan untuk melihat hubungan sebab akibat yang ditimbulkan antara kebutuhan dan keinginan konsumen (customer needs) dengan karakteristik teknik (technical Response). Simbol dari hubungan matriks ini adalah :

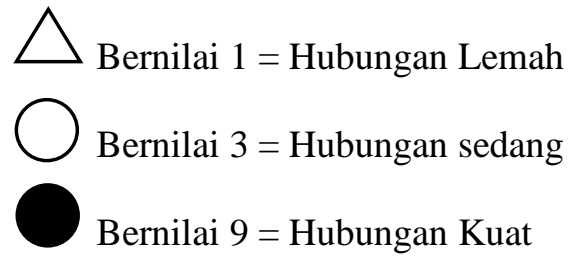

10. Matriks Teknik (Technical Matrix)

Tahap ini merupakan proses penentuan prioritas teknik. Prioritas teknik ini akan menjadi bahan pertimbangan cafe dalam proses perancangan karakteristik teknik.

\section{HASIL DAN PEMBAHASAN \\ Pengumpulan Data Responden}

Total responden dalam penelitian ini terbagi atas 2 jenis responden, yaitu responden dari pihak pengelola cafe untuk menentukan matriks persyaratan teknis, nilai sasaran atau planning serta poin penjualan, lalu responden dari pengunjung cafe xyz dimana, dalam penelitian ini berjumlah 52 orang yang telah dilakukan uji kecukupan data menggunakan metode slovin dengan jumlah sampel minimum sebanyak 49 responden. Karakteristik pengunjung yang menjadi responden dalam penelitian ini. dapat dilihat berdasarkan jenis kelamin, usia, pekerjaan serta frekuensi berkunjung.

\section{Uji Validitas dan Reliabilitas}

Berdasarkan hasil uji validitas menggunakan spss 23 dengan jumlah responden sebanyak 52 orang dan tingkat signifikansi sebesar 5\% serta $\mathrm{df}=\mathrm{n}-2=50$. Maka didapatkan bahwa hasil dari nilai rhitung dari setiap pertanyaan dalam kuesioner kepentingan serta kepuasan pelayanan cafe XYZ lebih besar dari $r$ tabel. Dengan demikian seluruh atribut pertanyaan tersebut dapat di katakan valid. Dapat dilihat pada tabel 3 
Alloysius Vendhi Prasmoro, Chusnul Chotimah, Denny Siregar

Submitted: 09/10/2020; Revised: 10/10/2020; Accepted: 12/10/2020; Published: 29/12/2020

Tabel 3 Uji Validitas

\begin{tabular}{crrrrc}
\hline \multirow{2}{*}{$\begin{array}{c}\text { Item } \\
\text { Pertanyaan }\end{array}$} & $\begin{array}{c}\text { r- } \\
\text { tabel }(5 \%)\end{array}$ & $\begin{array}{c}\text { Kepentingan } \\
\text { hitung }\end{array}$ & keterangan & \multicolumn{2}{c}{ Kepuasan } \\
hitung & keterangan \\
\hline N1 & 0,2353 & 0,695 & VALID & 0,852 & VALID \\
N2 & 0,2353 & 0,769 & VALID & 0,806 & VALID \\
N3 & 0,2353 & 0,815 & VALID & 0,628 & VALID \\
N4 & 0,2353 & 0,723 & VALID & 0,726 & VALID \\
N5 & 0,2353 & 0,724 & VALID & 0,421 & VALID \\
N6 & 0,2353 & 0,736 & VALID & 0,781 & VALID \\
N7 & 0,2353 & 0,845 & VALID & 0,740 & VALID \\
N8 & 0,2353 & 0,739 & VALID & 0,720 & VALID \\
N9 & 0,2353 & 0,819 & VALID & 0,692 & VALID \\
N10 & 0,2353 & 0,788 & VALID & 0,826 & VALID \\
N11 & 0,2353 & 0,455 & VALID & 0,718 & VALID \\
N12 & 0,2353 & 0,785 & VALID & 0,459 & VALID \\
N13 & 0,2353 & 0,630 & VALID & 0,748 & VALID \\
N14 & 0,2353 & 0,880 & VALID & 0,642 & VALID \\
N15 & 0,2353 & 0,747 & VALID & 0,701 & VALID \\
\hline
\end{tabular}

Uji reliabilitas digunakan untuk mengetahui sejauh mana konsistensi jawaban responden terhadap kepentingan dan kepuasan terhadap pelayanan cafeXYZ serta digunakan juga untuk menguji konsistensi terhadap kepuasan pelayanan di cafe kompetitor yakni cafe 123. Pada pengujian ini menggunakan Cronbach's Alpha pada SPSS 23. Dapat disimpulkan bahwa instrumen tersebut cukup konsisten dimana cronbach's alpha lebih dari 0.60. Berikut ini adalah hasil uji reliabilitas dengan menggunakan SPSS 23 pada tabel 4 sebagai berikut.

Tabel 4 Uji Reliabilitas

\begin{tabular}{ccc}
\hline Atribut & $\begin{array}{c}\text { Cronboach's } \\
\text { Alpha }\end{array}$ & $\begin{array}{c}\mathrm{N} \text { of } \\
\text { Item }\end{array}$ \\
\hline $\begin{array}{c}\text { Nilai Kepentingan } \\
\text { terhadap pelayanan } \\
\text { café XYZ }\end{array}$ & 0,939 & 15 \\
$\begin{array}{c}\text { Kepuasan pelayanan } \\
\text { terhadap Café XYZ }\end{array}$ & 0,924 & 15 \\
$\begin{array}{c}\text { Kepuasan pelayanan } \\
\text { terhadap Café XYZ }\end{array}$ & 0,942 & 15 \\
\hline
\end{tabular}

\section{Metode Quality Function Deployment}

1. Voice Of Customer

Tujuan dari penggunaan metode quality function deployment adalah untuk mengetahui atribut keinginin pelanggan (Voice of Customer). Berikut adalah voice of customer yang di gunakan untuk menganalisis kepuasan pelanggan di cafe XYZ. Tabel 5 adalah hasil dari voice of customer.

2. Penilaian Kepentingan Kepuasan Terhadap Pelayanan di Cafe XYZ dan Cafe Kompetitor (Cafe 123)

Penilaian kepentingan serat kepuasan pelanggan terhadap cafe XYZ dan cafe kompetitor didapat dari hasil kuesioner, pengunjung cafe XYZ dan beberapa pengunjung yang pernah mengunjungi atau mengetahui cafe 123. Tabel 6 adalah nilai hasil kuesioner 
Tabel 5 Voice of Customer

\begin{tabular}{ll}
\hline $\mathbf{N}$ & \multicolumn{1}{c}{ Voice of Customer } \\
\hline & Penampilan pelayan yang rapi dan \\
1 & menarik \\
& Fasilitas memadai, bersih dan lengkap \\
2 & (wifi, tempat diskusi, dan hiburan) \\
3 & cita rasa menu lezat dan fresh \\
4 & Platting menu menarik \\
5 & Menu tidak monoton \\
6 & Suasana aman dan nyaman \\
7 & Kualitas menu selalu terjaga \\
8 & Respon pelayan yang baik \\
9 & Pelayan bersikap ramah dan sopan \\
1 & Perhatian yang baik kepada seluruh \\
0 & pelanggan \\
1 & \\
1 & Selalu mendengan kritik dan saran \\
1 & Kesigapan pelayan dalam melayani \\
2 & pesanan baik itu take away \\
1 & Kemampuan pelayan dalam \\
3 & menginformasikan menu \\
1 & Kecepatan pelayan dalam menyajikan \\
4 & order pelanggan \\
1 & Kemudahan dalam melakukan \\
5 & pembayaran \\
\hline
\end{tabular}

Nilai target merupakan nilai tujuan yang dijadikan sebagai target oleh pihak manajemen cafe XYZ terhadap penilaian kepuasan yang diberikan oleh responden. Nilai rasio perbaikan adalah perbandingan antara nilai target dan nilai kepuasan konsumen yang bertujuan untuk mengetahui nilai yang harus dicapai oleh pengelola cafe untuk mencapai nilai target yang telah telah ditetapkan. Untuk mencari nilai rasio perbaikan pada setiap atribut dihitung dengan rumus persamaan 2 sebagai berikut.

imrpovement ratio $=\frac{\text { Nilai } \text { Target }}{\text { Nilai } \text { Kepuasan }}$

Contoh perhitungan pada atribut pertanyaan ke 1 "Penampilan karyawan rapi dan menarik". Improvement ratio $=\frac{4}{3.6}=1.11$

Poin penjualan (sales point) ditentukan oleh pihak pengelola cafe XYZ. Poin penjualan ini menggambarkan tingkat kepentingan yang dapat diperoleh apabila dilakukan peningkatan terhadap atribut kebutuhan konsumen. Nilai sales point paling yang digunakan yaitu :
1 = Tidak ada penjualan
$1.2=$ Penjualan sedang
$1.5=$ Penjualan ketat

Tabel 6 Nilai Hasil Kuesioner

\begin{tabular}{cccc}
$\begin{array}{c}\text { Atribut pertanyaan } \\
\text { (Voice of } \\
\text { Customer) }\end{array}$ & Nilai Kepentingan & $\begin{array}{c}\text { Nilai Kepuasan } \\
\text { Café XYZ }\end{array}$ & $\begin{array}{c}\text { Nilai Kepuasan } \\
\text { Kompetitor Café 123 }\end{array}$ \\
\hline 1 & 4,4 & 3,6 & 3,4 \\
2 & 4,6 & 4,0 & 3,7 \\
3 & 4,6 & 4,0 & 3,5 \\
6 & 4,5 & 3,9 & 3,6 \\
7 & 4,6 & 4,0 & 3,6 \\
8 & 4,5 & 3,6 & 3,7 \\
9 & 4,6 & 4,0 & 3,7 \\
10 & 4,4 & 4,0 & 4 \\
11 & 4,2 & 3,5 & 3,8 \\
12 & 4,4 & 3,4 & 3,6 \\
13 & 4,3 & 3,5 & 3,2 \\
14 & 4,4 & 3,7 & 3,6 \\
15 & 4,4 & 4,1 & 3,4 \\
\hline
\end{tabular}


Alloysius Vendhi Prasmoro, Chusnul Chotimah, Denny Siregar

Submitted: 09/10/2020; Revised: 10/10/2020; Accepted: 12/10/2020; Published: 29/12/2020

Tabel 7 Nilai Target dan Improvement Ratio, Poin Penjualan

Atribut pertanyaan
(Voice of Customer) Nilai Target $\quad$ Rasio Perbaikan Poin Penjualan

\begin{tabular}{cccc}
\hline 1 & 4 & 1,1 & 1,2 \\
2 & 4 & 1,0 & 1,5 \\
3 & 5 & 1,25 & 1,5 \\
6 & 4 & 1,1 & 1,2 \\
7 & 4 & 1,0 & 1,5 \\
8 & 4 & 1,03 & 1,5 \\
9 & 4 & 1,0 & 1,5 \\
10 & 4 & 1,11 & 1,5 \\
11 & 4 & 1,0 & 1,5 \\
12 & 4 & 1,0 & 1,5 \\
13 & 4 & 1,14 & 1,5 \\
\hline
\end{tabular}

3. Perhitungan Bobot Atribut Jasa (Absolute Weight) dan Normalisasi Bobot (\% of weight)

Absolute weight merupakan pembobotan yang dilakukan untuk mengetahui urutan atribut mana yang akan ditingkatkan. Untuk menentukan bobot setiap atribut dihitung dengan rumus persamaan 3 sebagai berikut.

Absolute weight $=B_{X} C_{X} D$

Keterangan:

$B=$ Importance Rating

$C=$ Improvement Ratio

$D=$ Sales point

Contoh perhitungan absolute weight pada atribut layanan yang pertama "penampilan karyawan rapi dan menarik" adalah :

Absolute weight $=4.4 \times 1.11 \times 1.2=5.87$

Dari perhitungan pada absolute weight yang telah diperoleh maka selanjutnya perlu dilakukan normalisasi bobot yang bertujuan untuk memudahkan penentuan terhadap atribut mana yang perlu dilakukan perkembangan atau perbaikan. Perhitungan normalisasi bobot dihitung dengan membagi bobot pada satu atribut dengan total bobot secara keseluruhan. Setiap atribut dihitung dengan rumus persamaan 4 berikut.

Normalisasi bobot $=\frac{\text { Bobot }}{\text { Total bobot }}$
Contoh perhitungan \% of weight pada atribut layanan pertama "penampilan karyawan rapi dan menarik". Adalah sebagai berikut :

$\sum$ bobot $=5.87+6.90+8.63+5.45+6.60+$ $6.92+6.90+7.50+6.90+6.60+7.20+$ $7.76+5.90+7.14+5.15=101.41$

Normalisasi bobot $=\frac{5.87}{101.41}=0.06$

Tabel 8 Absolute Weight dan \% of weight

Atribut pertanyaan

(Voice of

Customer)

\begin{tabular}{crr}
\hline 1 & 5,87 & 0,06 \\
2 & 6,9 & 0,07 \\
3 & 8,63 & 0,09 \\
6 & 5,45 & 0,05 \\
7 & 6,6 & 0,07 \\
8 & 6,92 & 0,07 \\
9 & 6,9 & 0,07 \\
10 & 7,5 & 0,07 \\
11 & 6,9 & 0,07 \\
12 & 6,9 & 0,08 \\
13 & 7,2 & 0,06 \\
14 & 7,76 & 0,07 \\
15 & 5,17 & 0,05 \\
\hline
\end{tabular}

Analisis Perbaikan Kualitas Pelayanan Menggunakan Metode Quality Function Deployment (Studi Kasus Cafe XYZ Rawalumbu) Journal of Industrial and Engineering System 1 (2): Desember 2020 
5. Persyaratan Teknis

Merupakan upaya pihak manajemen cafe dalam merespons kebutuhan pelanggan. Berdasarkan informasi yang diperoleh melalui wawancara dengan pihak manajemen cafe XYZ maka diperoleh delapan butir Persyaratan teknis yang sesuai dengan kemampuan pengelola cafe dalam menyelesaikan permasalahan pada penelitian ini. Sebagai berikut:

1. Evaluasi keadaan cafe.

2. Tersedia keluhan dan saran

3. Penyediaan fasilitas cafe

4. Penyajian

5. Memperhatiakan kebersihan dan keindahan fasilitas cafe

6. Training karyawan

7. Suplai bahan baku

8. Pemasakan

6. Hubungan Matriks Kebutuhan Pelanggan serta Respons Teknis

Matriks kebutuhan pelanggan (what) merupakan pernyaataan terhadap keinginan konsumen (voice of customer) dan matriks respons teknis (hows) merupakan jawaban atau upaya pengelola cafe XYZ dalam merespons kebutuhan pelanggan. sehingga menimbulkan keterkaitan atau hubungan antara kedua matriks ini. Jika hubungannya sangat kuat maka nilainya 9. jika hubungannya sedang bernilai 3 dan jika hubungan lemah bernilai 1. Matriks hubungan what's dan how's selengkapnya dapat dilihat pada Gambar 1

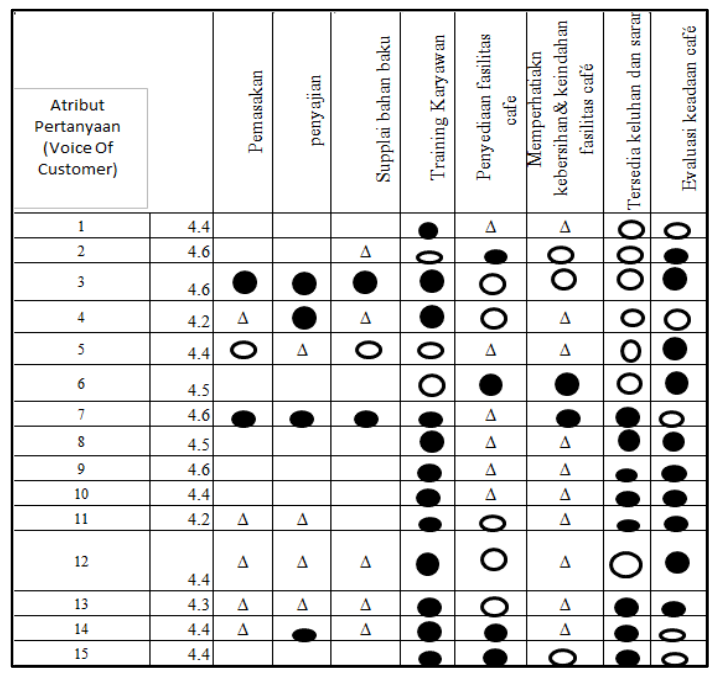

Gambar 1 Hubungan Persyaratan Teknis
7. Pengembangan Hubungan antar Matriks Hows

Matriks hows merupakan jawaban terhadap pertanyaan matriks what's (voice of customer) untuk analisis kepuasan pelayanan di cafe XYZ. Perhatikan gambar berikut.

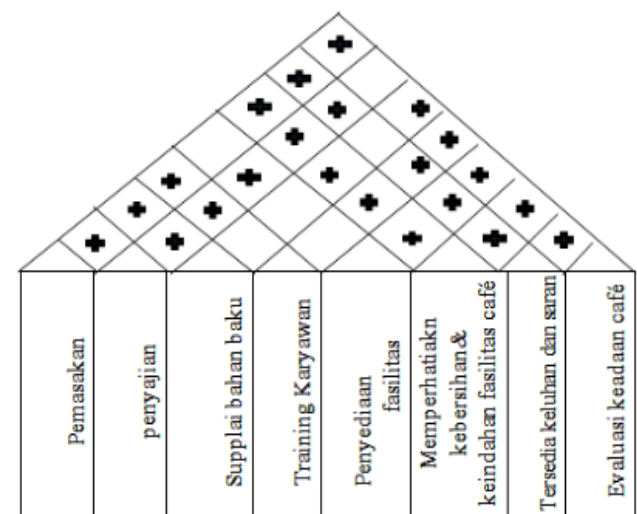

Gambar 2 Hubungan antar Parameter Teknik

Nilai kepentingan Teknis (Technical Priorities) dan $\%$ of total priorities. Perhitungan pada nilai kepentingan teknis bertujuan untuk mengetahui mana prosedur persyaratan teknis yang menjadi prioritas. Contoh perhitungan ini adalah pada atribut persyaratan teknis nomor satu “ pemasakan". Gambar 1 untuk mengetahui simbol hubungan pada atribut voice of customer dan persyaratan teknis.

Technical Priorities $=\mathrm{a} \times \mathrm{Abs}$

Keterangan:

$\mathrm{a}=$ Nilai parameter teknis yang memiliki simbol hubungan dengan voice of customer Abs $=$ Absolut Weight

Technical Priorities $=(9 \times 8.63)+(1 \mathrm{x}$ $5.45)+(3 \times 6.60)+(9 \times 6.90)+(1 \times 7.20)$ $+(1 \mathrm{X} 7.76)+(1 \mathrm{x} 5.90)+(1 \mathrm{x} 7.14)=186.4$ Untuk mencari \% of total priorities pada setiap atribut dihitung dengan rumus persamaan 6 berikut.

$\%$ of total priorities $=\frac{\text { technical priorities }}{\text { Stechnical priorities }}$

$\%$ of total priorities $=\frac{186.4}{2877.14}=0.06$

Tabel 9 adalah \% of Total Priorities 
Alloysius Vendhi Prasmoro, Chusnul Chotimah, Denny Siregar

Submitted: 09/10/2020; Revised: 10/10/2020; Accepted: 12/10/2020; Published: 29/12/2020

Tabel 9 Nilai \% Of Total Priorities

\begin{tabular}{llll}
\hline No & $\begin{array}{l}\text { Persyaratan } \\
\text { Teknis }\end{array}$ & $\begin{array}{l}\text { Technical } \\
\text { priorities }\end{array}$ & $\begin{array}{l}\% \text { of } \\
\text { total } \\
\text { priorities }\end{array}$ \\
\hline 1 & Pemasakan & 186.4 & 0.06 \\
2 & $\begin{array}{l}\text { Penyajian } \\
269.7\end{array}$ & 0.09 \\
3 & $\begin{array}{l}\text { Suplai bahan } \\
\text { baku }\end{array}$ & 192.7 & 0.07 \\
4 & $\begin{array}{l}\text { Training } \\
\text { karyawan }\end{array}$ & 241 & 0.08 \\
5 & $\begin{array}{l}\text { Penyediaan } \\
\text { fasilitas cafe }\end{array}$ & 380.2 & 0.13 \\
6 & $\begin{array}{l}\text { Memperhatikan } \\
\text { kebersihan dan } \\
\text { keindahan }\end{array}$ & & 0.09 \\
fasilitas cafe & & \\
7 & $\begin{array}{l}\text { Tersedia } \\
\text { keluhan dan } \\
\text { saran }\end{array}$ & & \\
8 & $\begin{array}{l}\text { Evaluasi } \\
\text { keadaan cafe }\end{array}$ & 729.7 & 0.22 \\
\hline
\end{tabular}

\section{Usulan Perbaikan terhadap Voice of customer}

Berdasarkan tabel perhitungan voice of customer maka improvement technic (teknis perbaikan) pada masing masing atribut yang telah dilakukan perhitungan persentase bobot total terhadap 5 dimensi /variabel dari persyaratan pelanggan (voice of customer) berdasarkan urutan skala prioritas dari persentse terbesar adalah sebagai berikut :

1. Dimensi Tangible (Bukti Fisik). Terdiri dari 5 atribut voice of customer yaitu: penampilan karyawan rapi dan menarik, fasilitas memadai (wifi, tempat diskusi dan hiburan, dll), cita rasa menu lezat dan fresh, plating menu menarik, menu tidak monoton. Hal yang perlu dilakukan pada dimensi ini adalah:

a. Memberikan seragam kepada karyawan cafe XYZ agar penampilan terlihat lebih rapi dan menarik, menetapkan standar dalam berpenampilan bagi karyawan cafe XYZ.

b. Melakukan perawatan serta penambahan terhadap fasilitas cafe seperti perbaikan wifi agar jaringan lebih baik, penyediaan tempat diskusi yang nyaman, penyediaan fasilitas hiburan berupa beberpa games dan live music, dsb.

c. Melakukan pelatihan terhadap koki atau melakukan recruitment terhadap koki baru untuk cafe XYZ yang sudah berpengalaman baik dalam pemasakan maupun penyajian sehinggan plating menu- terlihat menarik bukan hanya rasa yang enak saja.

d. Menjaga kualitas bahan baku baik pada saat suplai bahan baku dan penyimpanan dengan suhu yang sesuai untuk berbagai bahan baku.

e. Rutin melakukan evaluasi terhadap menu yang ada baik dari segi rasa atau pun penambahan menu baru yang dapat menarik minat pelanggan.

2. Dimensi Assurance (Jaminan). Terdiri dari 2 atribut persyaratan pelanggan yaitu: suasana aman dan nyaman dan kualitas menu selalu terjaga. Hal yang perlu dilakukan pada dimensi ini adalah sebagai berikut:

a. Mengaktifkan CCTV untuk menjamin keamanan cafe sampai dengan tempat parkir pengunjung cafe XYZ

b. Penataan suasana dan desain ruang agar lebih bersih, rapi dan menarik, serta live music dengan suasana dan volume yang sesuai supaya membuat pengunjung merasa nyaman

c. Melakukan periode penjadwalan belanja atau suplai bahan baku berdasarkan lamanya bahan baku bisa stok dalam kurun waktu tertentu, supaya kualitas menu selalu terjaga

d. Menyimpan bahan baku berdasarkan suhu ketahanan bahan baku dapat disimpan, supaya kualitas menu selalu terjaga.

3. Dimensi Responsiveness (Daya Tanggap). Dimensi ini terdiri dari 2 atribut persyaratan pelanggan yaitu: respons pelayan yang baik dan pelayan bersikap ramah dan sopan. Hal yang perlu dilakukan pada perbaikan dimensi ini adalah:

a. Melakukan pelatihan terhadap pelayan tentang bagaimana Respons dan sikap yang sopan dalam melayani pelanggan.

b. Menerapkan sistem poin terhadap pelayan cafe XYZ, jika kinerja baik Analisis Perbaikan Kualitas Pelayanan Menggunakan 
Alloysius Vendhi Prasmoro, Chusnul Chotimah, Denny Siregar

Submitted: 09/10/2020; Revised: 10/10/2020; Accepted: 12/10/2020; Published: 29/12/2020

maka poin bertambah dan akan mendapatkan reward dari pihak manajemen cafe bagi peraih poin tertinggi, begitupun sebaliknya jika kinerja pelayan kurang baik maka akan mendapatkan poin minus dan akan mendapatkan hukuman ringan berupa teguran atau pemotongan gaji jika mendapat poin minus serta bisa diberhentikan apabila sering melakukan kesalahan.

4. Empathy (Empati). Dimensi ini terdiri dari 2 atribut persyaratan pelanggan yaitu: perhatian yang baik kepada seluruh pelanggan dan selalu mendengar keluhan dan saran. Hal yang perlu dilakukan pada dimensi ini adalah sebagai berikut:

a. Menanamkan rasa empati kepada pelayan cafe serta memberikan evaluasi tentang perlakuan terhadap pengunjung cafe tanpa membedakan satu sama lain dalam memberikan perhatian yang baik kepada pelanggan.

b. Mengaktifkan kotak keluhan dan saran terhadap pelanggan yang berkunjung ke cafe XYZ. Sehingga dapat dijadikan barometer saat evaluasi rutin.

c. Dimensi Reliability (Kehandalan). Dimensi ini terdiri dari 4 atribut persyaratan pelanggan yaitu: kesigapan pelayan dalam melayani pesanan baik itu take away, kemampuan pelayan dalam menginformasikan menu, kecepatan pelayan dalam menyajikan order pelanggan dan kemudahan dalam melakukan pembayaran. Hal yang perlu dilakukan pada dimensi ini adalah sebagai berikut:

d. Melakukan pelatihan terhadap pelayan tentang bagaimana kordinasi yang cepat dengan koki agar tentang menyajikan menu. Sehingga pengunjung tidak butuh waktu lebih dari 15-20 menit dalam menunggu pesanan yang datang atau siap untuk take away.

e. Mengaktifkan sistem pembayaran elektronik seperti kartu debit, ovo, gopay, dana, dll.

f. Menerapkan sistem poin terhadap pelayan cafe XYZ, jika kinerja baik maka point bertambah dan akan mendapatkan reward dari pihak manajemen cafe bagi peraih poin tertinggi, begitupun sebaliknya jika kinerja pelayan kurang baik maka akan mendapatkan poin minus dan akan mendapatkan hukuman ringan berupa teguran atau pemotongan gaji jika mendapat poin minus serta bisa diberhentikan apabila sering melakukan kesalahan.

\section{KESIMPULAN DAN SARAN KESIMPULAN}

Kesimpulan yang diperoleh dalam penelitian terhadap analisis kualitas pelayanan di cafe XYZ adalah skala prioritas yang harus dilakukan perbaikan untuk pengembangan cafe XYZ berdasarkan voice of customer adalah : cita rasa menu lezat dan fresh, kesigapan pelayan dalam melayani pesanan baik itu take away, respons pelayan yang baik, selalu mendengar keluhan dan saran. Sedangkan berdasarkan hasil wawancara antara penulis dengan pihak manajemen cafe di dapat 8 persyaratan teknis yaitu evaluasi keadaan cafe, tersedia keluhan dan saran, penyediaan fasilitas cafe, penyajian, kebersihan dan keindahan, training, suplai bahan baku dan pemasakan.

\section{SARAN}

Untuk meningkatkan kualitas cafe XYZ sebaiknya hal yang perlu dilakukan oleh pihak pengelola cafe XYZ adalah mengevaluasi keadaan cafe secara rutin, memperhatikan keluhan dan saran dari pelanggan dan sebaiknya pihak manajemen cafe memberikan reward atau penghargaan terhadap karyawan yang bekerja dengan baik setiap tahunnya.

DAFTAR PUSTAKA.

Adieba. M. H. \& Dwiyanto. B. M. (2016). Analisis Peningkatan Kualitas Produk Batik Menggunakan Pendekatan Quality Function Deployment (QFD) (Studi Kasus Batik BL Di Pekalongan). Diponegoro Journal Of Management. 5. 1-12.

Ervini. M \& Moektiwibowo. H. (2018). Analisis Quality Function Deployment (Qfd) Guna Meningkatkan After Sales Spare Parts \& Service Lift. 92-114.

Hakim. A. L. (2017). Analisis Kualitas Layanan dengan Metode Quality Function Deployment (Qfd) (Studi Kasus: J\&T Express. Cabang Benowo-Surabaya). Seminar Nasional Inovasi Dan Aplikasi Teknologi Di Industri. 18. 11-20. 
Permatadeny. A. \& Andy. J. (2017). Perancangan Dan Pengembangan Produk Kopi Untuk Meningkatkan Kualitas Pemasaran. Seminar Nasional Inovasi Dan Aplikasi Teknologi Di Industri.

Pratiwi. C. G. \& Susanty. A. (2017). Analisis Kepuasan Pelanggan Menggunakan Metode Importance Performance Analysis Dan Quality Function Deployment Di Hypermarket Super Indo Tembalang. Semarang. Industrial Engineering Online Journal. 6. 2-3.

Ridlo. R., Warso. M \& Fathoni. A. (2016). Pengaruh Kualitas Pelayanan Terhadap Kepuasan (Studi Kasus pada Konsumen PT. Graha Service Indonesia Cabang Semarang). Journal of Management. 2. 7.

Santosa. A. T. (2019). Pengaruh Kualitas Kelayanan Kualitas Produk Store Atmosphere dan E-wom Terhadap Proses Keputusan Kembelian (Survei Terhadap Konsumen Zenbu-House Of Mozaru Paris Van Java. bandung). Jurnal Manajemen Maranatha. 18. 143-158.

Sariffudin. R. (2017). Analisis Kualitas Layanan Penyerapan Aspirasi Anggota DPR RI Dengan Pendekatan Quality Function Deployment (QFD). Jurnal Sistem dan Manajemen Industri. 1. 73-78.

Silalahi. R. V., Kristian. H. J. \& Prathama. K. (2017). Integrasi Analisis PerformanceImportance Dan House Of Quality Dalam Upaya Peningkatan Kualitas Di Kafe Two Stories Bogor. Journal Industrial Servicess. 3.

Syahri. D., Pratama. M. I., \& Gustiara. Y. (2018). Pengaruh Kualitas Produk dan Kualitas Pelayanan Terhadap Kepuasan Konsumen Bistroran Karibia Sea Food Medan. 6.

Wijaya. T. (2018). Manajemen Kualitas Jasa Desain Servqual.QFD dan Kano edisi 2. (B. Sarwiji. Ed.) Jakarta Barat: Penerbit Indeks Jakarta. 